\title{
Synthesis and characterization of flexible and high-temperature resistant polyimide aerogel with ultra-low dielectric constant
}

\author{
X. M. Zhang ${ }^{1 *}$, J. G. Liü ${ }^{2}$, S. Y. Yang ${ }^{2}$ \\ ${ }^{1}$ School of Electrical Engineering, Beijing Jiaotong University, 100044 Beijing, China \\ ${ }^{2}$ Laboratory of Advanced Polymer Materials, Institute of Chemistry, Chinese Academy of Sciences, 100190 Beijing, \\ China
}

Received 10 March 2016; accepted in revised form 2 May 2016

\begin{abstract}
A polyimide (PI) aerogel with excellent combined thermal and dielectric properties was successfully prepared by the polycondensation of 3,3',4,4'-biphenyltetracarboxylic dianhydride (BPDA), 5-amino-2-(4-aminophenyl)benzoxazole (APBO) and octa(amino-phenyl)silsesquioxane (OAPS) crosslinker, followed by a supercritical carbon dioxide $\left(\mathrm{scCO}_{2}\right)$ drying treatment. The developed PI aerogel exhibited an ultra-low dielectric constant $(k)$ of 1.15 at a frequency of $2.75 \mathrm{GHz}$, a volume resistivity of $5.45 \cdot 10^{14} \Omega \cdot \mathrm{cm}$, and a dielectric strength of $132 \mathrm{kV} / \mathrm{cm}$. The flexible PI aerogel exhibited an openpore microstructure consisting of three-dimensional network with tangled nanofibers morphology with a porosity of $85.6 \%$ (volume ratio), an average pore diameter of $19.2 \mathrm{~nm}$, and a Brunauer-Emmet-Teller (BET) surface area of $428.6 \mathrm{~m}^{2} / \mathrm{g}$. In addition, the PI aerogel showed excellent thermal stability with a glass transition temperature $\left(T_{\mathrm{g}}\right)$ of $358.3{ }^{\circ} \mathrm{C}$, a $5 \%$ weight loss temperature over $500^{\circ} \mathrm{C}$, and a residual weight ratio of $66.7 \%$ at $750{ }^{\circ} \mathrm{C}$ in nitrogen.
\end{abstract}

Keywords: thermal properties, polyimide aerogel, supercritical drying, dielectric properties

\section{Introduction}

In the past decades, polymer dielectrics with low dielectric constant (low-k) and low dissipation factor features have been paid increasing attention in ultralarge scale integrated circuit (ULSI) fabrication due to their abilities to lower the line-to-line noise in interconnects and alleviate power dissipation issues by reducing the capacitance between the interconnect conductor lines so as to achieve faster signal transmission speed [1-3]. Among various polymer dielectrics, polyimides (PIs) have been investigated more extensively as high performance interlayer dielectrics (ILDs) than most other polymers due to their desirable high-temperature stability, excellent mechanical and dielectric properties for ULSI fabrications [4-6]. However, conventional PI dielectrics usu- ally have $k$ values around 3.0, which cannot meet the rapid development of ULSI assembly. For example, according to the prediction of International Technology Roadmap for Semiconductors (ITRS), by 2016, a $k$ value below 2.0 at $1 \mathrm{GHz}$ and a dielectric loss below 0.003 have to be met for the ILDs [7]. It has been proven that the common methodologies reducing the $k$ values for conventional PIs $(k \approx 3.0)$, including introduction of substituents with low molar polarizability (fluorinated groups, alicyclic groups, etc.) or with large molar volumes (phenyl, fluorene, etc.) could only achieve a lowest $k$ value around 2.5 [8].

In recent years, it was found that incorporation of air voids $(k=1.0)$ into the polymers is efficient to achieving a $k$ value less than 2.0. Thus, various macroporous,

$\overline{{ }^{*} \text { Corresponding author, e-mail: xmzhang@bjtu.edu.cn }}$

(C) BME-PT 
mesoporous or nanoporous low- $k$ polymer films have recently been very attractive for ILD applications to reduce $k$ to a minimum value [9]. By this methodology, various ultra low- $k$ PIs have been reported [10 14]. However, the attempts further reducing the $k$ values of PIs below 1.5 seem to be more challenging because the conventional methods could only achieve a very limited air loading ( $<60 \%$, volume ratio).

Very recently, aerogel dielectrics have been becoming one of the most important research topics for high performance ILDs using in ULSI due to their extremely high porosity, low density, low thermal conductivity, and ultra-low dielectric constants [15]. The porosity of an aerogel material can usually reach over $80 \%$ (volume ratio). The trapped air efficiently decreases the $k$ values of the aerogels to a low level extremely close to 1.0 for air. Among various aerogels, organic polymeric aerogels are more suitable to be used as ILDs for ULSI due to their intrinsically flexible and tough nature compared with their fragile inorganic counterparts, such as silica, alumina aerogels, etc. [16]. Various polymer aerogels, such as polyurethane, polyurea, polystyrene, and polydicyclopentadiene aerogels have been widely investigated in the literature and have been finding a variety of applications in high-tech fields [17]. However, common organic aerogels usually suffer from their low thermal and dimensional stability at elevated temperatures; thus cannot meet the severe demands of interlayer electrical insulation process for ULSI fabrications. Thus, as a representative high-temperature resistant organic aerogels, PI aerogels have been developed rapidly in recent years [18-22]. The dielectric constants and dissipation factors for PI aerogels have also been investigated in detail. For instance, Meador and coworkers studied the dielectric properties of PI aerogels and investigated their potential applications as substrates for lightweight patch antennas for aerospace applications [23, 24]. Relative $k$ values as low as 1.16 at a frequency of X-band ( 11-12 GHz) were obtained for PI aerogels made from 3,3',4,4'-biphenyl tetracarboxylic dianhydride (BPDA), 2,2'-dimethylbenzidine (DMBZ), and 1,3,5tris(4-aminophenoxy)benzene (TAB) crosslinker. Shen and coworkers have reported intrinsically highly-hydrophobic semi-alicyclic fluorinated PI aerogel with ultra-low $\mathrm{k}$ values of 1.17-1.19 in the frequency range of $2-12 \mathrm{GHz}$ [25].
The dielectric constants and dissipation factor of PI aerogels have been investigated in the literature; however, other dielectric behaviors for PI aerogels have been rarely addressed in the literature although they are also very important for their applications in ULSI. For example, in addition to low dielectric constants, the next generation of ILDs for submicron and nanolevel electronics must also satisfy a variety of other requirements, including high dielectric strength and resistivity, high thermal and dimensional stability, low moisture adsorption, and good adhesion to semiconductor and metal substrates in order to achieve high reliability [26]. As we know, for porous low- $k$ polymers, while increasing porosity can reduce the $k$ values; however, the dielectric strength is often adversely affected. To the best of our knowledge, the dielectric breakdown behavior for PI aerogels or even organic aerogels has been rarely involved in the literature. In the current paper, a PI aerogel was first prepared from BPDA, APBO and OAPS via a $\mathrm{scCO}_{2}$ drying procedure, and then the thermal and dielectric properties for the aerogel were investigated in detail. Especially the dielectric breakdown behavior for the aerogel was studied.

\section{Experimental}

\subsection{Materials}

3,3',4,4'-Biphenyltetracarboxylic dianhydride (BPDA) and 5-amino-2-(4-aminophenyl)-benzoxazole (APBO) were purchased from Tokyo Chemical Industry Co., Ltd. (TCI), Japan. BPDA was dried in vacuo at $180^{\circ} \mathrm{C}$ overnight prior to use and APBO was used as received. Octa(aminophenyl) silsesquioxane (OAPS) was purchased from Meilian Composite Co. Ltd., Liaoning, China and used as received. $\mathrm{N}$-methyl-2pyrrolidinone (NMP) was purified by vacuum distillation over $\mathrm{CaH}_{2}$ and stored over $0.4 \mathrm{~nm}$ molecular sieves prior to use. The other commercially available reagents were used without further purification.

\subsection{Characterization}

Fourier transform infrared (FT-IR) spectrum was obtained on a Bruker Tensor-27 FT-IR spectrometer. Field emission scanning electron microscopy (FESEM) was obtained on a Hitachi S-4800 microscope. PI aerogel surface area $(\sigma)$ and pore size distribution were measured by nitrogen adsorption and desorption at $77 \mathrm{~K}$ using a Micromeritics ASAP 2000 surface 
areas and porosity analyzer. Before testing, the PI aerogel sample was outgassed at $80^{\circ} \mathrm{C}$ for $10 \mathrm{~h}$ in vacuo. The surface area was calculated by BrunauerEmmet-Teller (BET) method and pore size distribution was calculated by Barret-Joyner-Halenda (BJH) method. The bulk density $\left(\rho_{\mathrm{b}}\right)$ and skeletal density $\left(\rho_{\mathrm{s}}\right)$ were measured by mercury intrusion porosimetry using a Micromeritics Auto Pore IV9520 porosimeter. The percent porosity was calculated as: porosity $(\%)=\left(1-\rho_{\mathrm{b}} / \rho_{\mathrm{s}}\right) \cdot 100$. The thermogravimetric analyses (TGA) were recorded on a TA-Q50 thermal analysis system at a heating rate of $20^{\circ} \mathrm{C} / \mathrm{min}$ in nitrogen. Thermal mechanical analyses (TMA) were performed on a TA-Q400 analyzer over $50-400{ }^{\circ} \mathrm{C}$ at a heating rate of $5{ }^{\circ} \mathrm{C} / \mathrm{min}$ in nitrogen. The compression properties of the PI aerogels were measured on an Instron 5567 according to the ASTM Standard D 695-10. The Young's modulus was determined as the initial linear portion of the slope of the stress-strain curve. The electrical insulation properties were measured on a PC68 digital high-voltage and high-resistance Megger instrument. The surface resistivity $\left(\rho_{\mathrm{s}}\right)$ and volume resistivity $\left(\rho_{\mathrm{v}}\right)$ of PI aerogel were measured according to ASTM D-257-91. The samples were dried at $120^{\circ} \mathrm{C}$ for $1 \mathrm{~h}$ prior to measurement. Dielectric strength of PI aerogel film $(d=2.5 \mathrm{~mm})$ were measured according to ASTM D-149-81, which were subjected to 60 cycles AC voltage at $100 \mathrm{~V} / \mathrm{s}$ rate of rise to the breakdown voltage. The broadband dielectric constant $(k)$ and dissipation factor $(\delta)$ is measured by an Agilent vector network analyzer (Model 8510) at room temperature. The frequency was in the range of $2-12 \mathrm{GHz}$ and the sample size was $50 \mathrm{~mm} \times 30 \mathrm{~mm} \times 2.5 \mathrm{~mm}$.

\subsection{Synthesis of PI aerogel}

To a three-necked $250 \mathrm{~mL}$ flask equipped with a mechanical stirrer, a nitrogen inlet and a cold water bath was charged with APBO (1.3885 g, $6.1644 \mathrm{mmol})$ and NMP $(25 \mathrm{~g})$ at $10-15^{\circ} \mathrm{C}$ under a nitrogen flow of $10 \mathrm{~mL} / \mathrm{min}$. After stirring for $20 \mathrm{~min}$, a clear solution was obtained. Then, BPDA (1.8722 g, $6.3632 \mathrm{mmol})$ was added in one batch and an additional volume of NMP (26 g) was added to wash the residual dianhydride and adjust the solid content of the reaction solution to be $6 \mathrm{wt} \%$. The cold water bath was removed after $2 \mathrm{~h}$. The mixture was stirred at room temperature for $12 \mathrm{~h}$ to yield a viscous poly(amic acid)
(PAA) solution. To the solution, OAPS $(0.0575 \mathrm{~g}$, $0.0497 \mathrm{mmol}$ ) was added and the reaction mixture was stirred at room temperature for another $12 \mathrm{~h}$ to afford a pale-brown viscous solution. Acetic anhydride $(3.1 \mathrm{~mL}, 31.6 \mathrm{mmol})$ and pyridine $(2.6 \mathrm{~mL}$, $31.6 \mathrm{mmol}$ ) were then added to the PAA solution. After stirring at room temperature for $30 \mathrm{~min}$, the solution was poured into pre-prepared molds. The molds were pre-made into various required shapes according to the demands of different measurement standards. For example, disk-shape molds were made for dielectric properties measurements; cylinder-shape for compression measurements; and rectangular shape for TMA measurements, etc.

The PAA solution gelled within $2 \mathrm{~h}$ and further aged for $24 \mathrm{~h}$ in the molds. Then, the gels were continuously immersed into a solution of $75 \%$ NMP in ethanol for $24 \mathrm{~h}$, then a $25 \% \mathrm{NMP}$ in ethanol for $24 \mathrm{~h}$, and finally a $100 \%$ ethanol for $24 \mathrm{~h}$. The obtained wet gels were then dried in a $160 \mathrm{~L}$ supercritical $\mathrm{CO}_{2}\left(\mathrm{scCO}_{2}\right)$ autoclave (maximum temperature: $80^{\circ} \mathrm{C}$; maximum pressure: $32 \mathrm{MPa}$; and maximum flow: $400 \mathrm{~L} / \mathrm{h}$ ) at the condition of $45^{\circ} \mathrm{C}$ under $15 \mathrm{MPa}$ for three cycles, $2 \mathrm{~h}$ each time. Then, the PI aerogel (BPDA/APBO/ OAPS) was dried in vacuo at $80^{\circ} \mathrm{C}$ for $24 \mathrm{~h}$ to afford the target aerogels as yellow monolithic solids with various shapes.

\section{Results and discussion}

\subsection{PI aerogel preparation}

A PI aerogel was designed and synthesized from rigid BPDA dianhydride, benzoxazole-containing APBO diamine, and POSS-containing OAPS crosslinking agent, as shown in Figure 1. Basically rigid molecular skeleton structures would guarantee the high thermal and dimensional stability for the PI aerogel. Introduction of benzoxazole moiety into the molecular structure of the PI aerogel via diamine monomer is to endow the polymer with good dielectric properties. As we know, polybenzoxazole (PBO) has an advantage over other polar high-temperature polymers (PI, polyamide, polybenzimidazole, etc.) due to the absence of polar groups in its repeating unit. The absence of polar groups in the polymer prevents the formation of hydrogen bond between the polymer and water, therefore resulting in less water absorption in the polymer and low dielectric constant $(<2.9$ at $1 \mathrm{MHz})$ and dielectric loss factor [27]. Ad- 
ditionally, PBO is also known for its excellent thermal and thermo-oxidative resistance, high electrical resistivity, and high dielectric strength over a long temperature period. Thus, the benzoxazole moiety in the current PI aerogel might provide various desir- able properties for the target aerogel. At last, OAPS was chosen to be an end-capper to crosslink the PI system affording the three-dimensional network microstructure. The nanoporous cage structure for OAPS is undoubtedly beneficial to decreasing the $k$ values

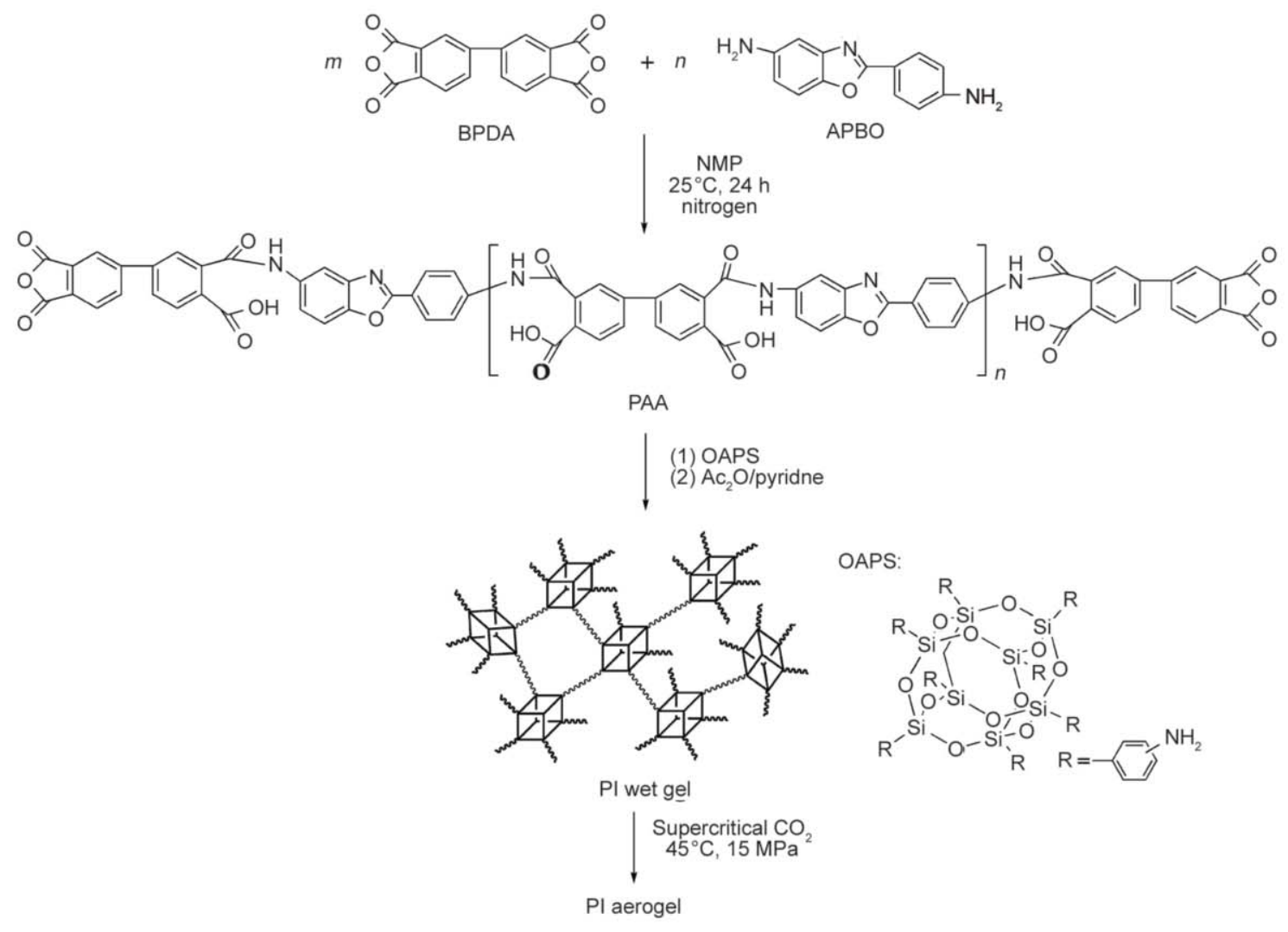

a)

PI (BPDA/APBO/OAPS)

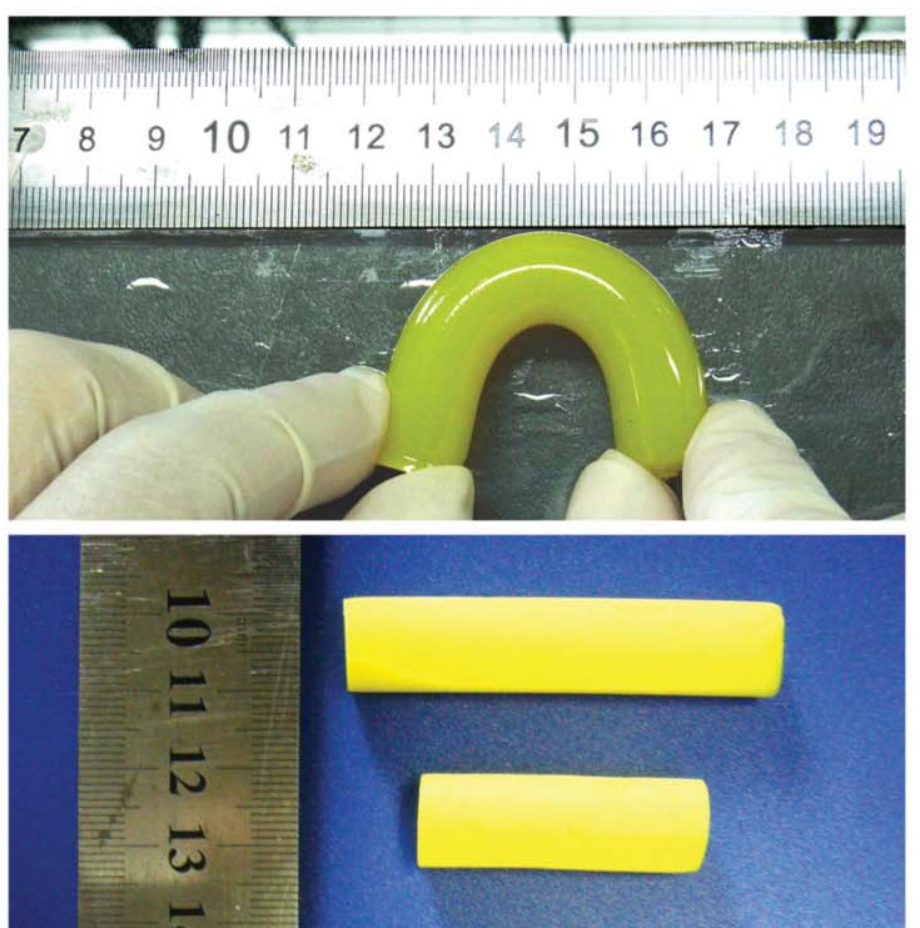

Figure 1. (a) Synthesis of PI (BPDA/APBO/OAPS) aerogel, (b) appearance of PI wet gel (above) and PI aerogel (below) 
for the PI aerogel. Actually, OAPS has been widely used as components to develop low- $k$ PI films. PI composite films with $\mathrm{k}$ values around 1.9 have been prepared by OAPS functionalized graphene oxide and PI matrix [28].

In the preparation, excessive BPDA was first reacted with APBO to give a anhydride-capped PI precursor, poly(amic acid) (PAA) solution. Then, OAPS was added into the PAA solution inducing a crosslinking reaction of the PAA. Dehydrating agent (acetic anhydride/pyridine system) was then added into the solution affording a PI wet gel. The PI wet gel exhibited excellent flexibility and toughness, which could be bent with a large radius of curvature (picture inserted in Figure 1). Then, the PI wet gel was immersed into ethanol to extract the NMP solvent. At last, the residual NMP and ethanol trapped in the gel was dried with $\mathrm{scCO}_{2}$ at $45^{\circ} \mathrm{C}$ with a pressure of $15 \mathrm{MPa}$ to give the final PI aerogel (Figure 1). This drying condition is more efficient and gentle than that of other supercritical fluids, such as supercritical ethanol (critical point: $\left.243^{\circ} \mathrm{C}, 6.38 \mathrm{MPa}\right)$. The prepared PI aerogel exhibited good mechanical properties. The stress-strain correlation in the compression tests indicated linear elastic regions below $10 \%$ strain and yielded in a relatively low slope for the aerogel. The compression stress of the PI aerogel at $10 \%$ strain is $0.92 \mathrm{MPa}$ and the Young's modulus is $18.2 \mathrm{MPa}$. These values are comparable to those mechanically strong PI aerogels reported in ref, [21]. The good mechanical properties for the PI aerogel are mainly attributed to the flexible and tough nature for the PI resin containing rigid biphenyl and benzoxazole moieties. In our experiments, PI aerogels with various shapes and sizes, including rods, films, sheets, and bulks were prepared for further measurements.

The chemical structures of the PI aerogel were identified by FT-IR measurements, illustrated in Figure 2. The characteristic absorption bands due to the vibration of the carbonyl groups $(\mathrm{C}=\mathrm{O})$ in the imide segments are clearly observed at 1766 and $1722 \mathrm{~cm}^{-1}$, which are assigned to the asymmetric and symmetric stretching vibrations, respectively. In addition, the stretching vibration of $\mathrm{C}-\mathrm{N}$ bond located at $1371 \mathrm{~cm}^{-1}$ and the imide ring deformation at $740 \mathrm{~cm}^{-1}$ further confirm the formation of PI. Meanwhile, the absence of absorbing band around $1855 \mathrm{~cm}^{-1}\left(v_{\mathrm{C}=\mathrm{O}}\right.$ in BPDA) indicated the complete reaction of the dianhydride.

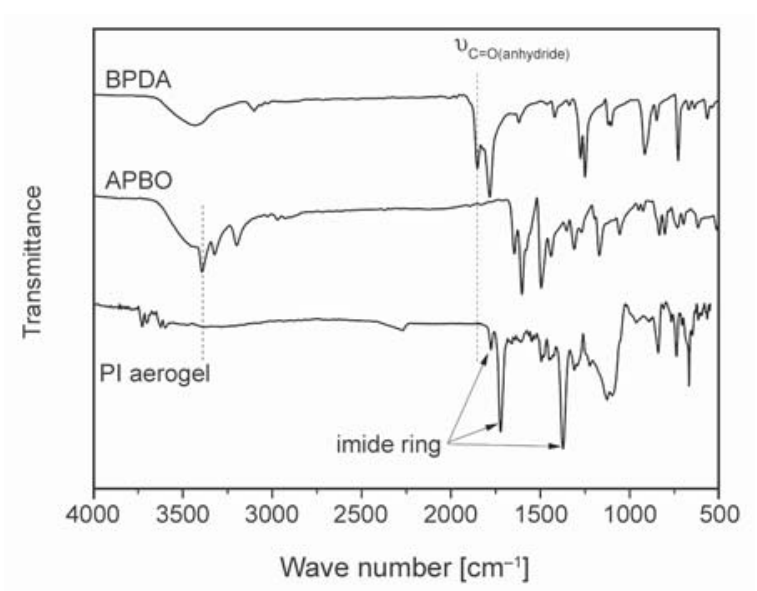

Figure 2. FT-IR spectra of PI aerogel and its crude materials

Similarly, absorbing bands around $3392 \mathrm{~cm}^{-1}\left(v_{\mathrm{N}-\mathrm{H}}\right.$ in APBO) and $1640 \mathrm{~cm}^{-1}\left(v_{\text {amide, }} \mathrm{C}=\mathrm{O}\right.$ in PAA) are also absent, indicating the completion reaction of the APBO and the successful conversion from the PAA precursors to PIs by chemical imidization.

\subsection{PI aerogel morphology}

The microtopography and physical parameters of the PI aerogel, including density, porosity, surface area, and volume shrinkage were investigated in detail. First, the FE-SEM measurement was performed to investigate the morphology of the PI aerogel, as shown in Figure 3. For the polymer, the open-pore structure consisting of three-dimensional networks with tangled nanofibers morphology having diameters at the nanometer scale were observed. This morphology determined the properties of the PI aerogel. The openpore structure might endow the aerogel with low density and low dielectric constants, while the three-dimensional networks tangled with nanofibers might provide good mechanical properties for the aerogel. The morphology-property correlations will be subsequently discussed in detail.

This three-dimensional network microstructures for the PI aerogel are mainly caused by the highly crosslinked structure of the molecular chains in the aerogel. The solvents in the networks were continuously extracted by the solvent exchange process and following supercritical drying procedures, leaving nano pores in the final aerogels. The volume of the PI aerogel shrinks $14.5 \%$ of its original value during the supercritical drying process. This value is comparable to the PI aerogels reported in the literature [29]. The low shrinkage and microtopography for the current 
aerogel prove that supercritical drying is an efficient procedure producing polymer aerogels. It has been established that supercritical fluids obtained above the critical point in temperature-pressure diagram enable drying the wet polymer gels without capillary stress due to absence of liquid-vapor interfaces in the phase [30]. In addition, $\mathrm{scCO}_{2}$ is a clean and versatile solvent, which has been widely used for the processing of a range of porous polymers due to the chemical, environmental, and economic advantages [31]. Using this technique, porosity higher than 85 $90 \%$ and dielectric constants below 1.5 can usually be obtained. Adversely, for other porous gels, such as Xerogels prepared by common drying techniques, the gels are easily collapsed by capillary stress induced

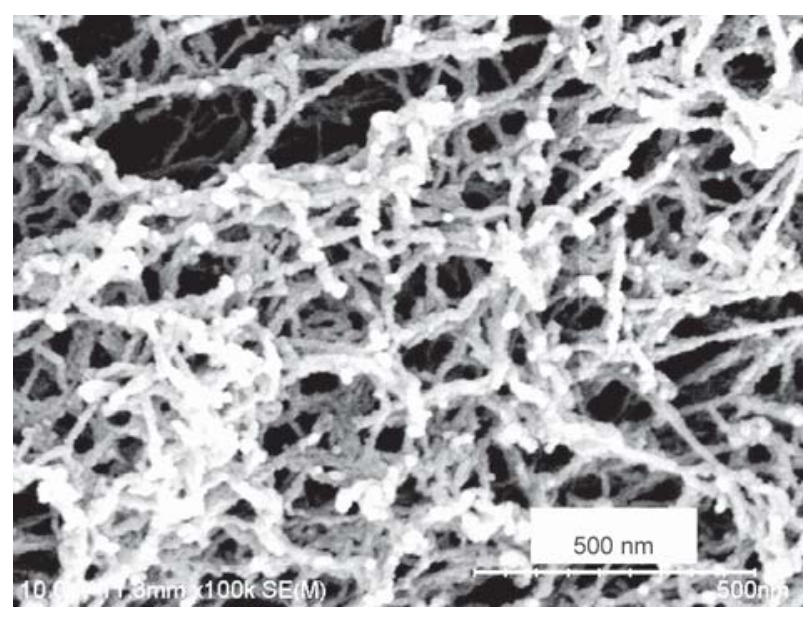

Figure 3. SEM image of PI aerogel at the liquid-vapor interfaces during drying process, resulting in apparent shrinkage for the nanoporous gels ( $>30 \%)$. The porosity is usually lower than 60 $80 \%$ and the $\mathrm{k}$ values are always higher than 1.50 $[32,33]$.

The structural parameters for PI aerogel are tabulated in Table 1 . The $\rho_{\mathrm{b}}$ and $\rho_{\mathrm{s}}$ values of PI aerogel were measured by mercury intrusion porosimetry method. The nanoporous structure for the aerogel endows them with low bulk density $\left(\rho_{\mathrm{b}}\right)$ of $0.21 \mathrm{~g} / \mathrm{cm}^{3}$. Air occupies the free empty space in the aerogel with a porosity of $85.6 \%$ as calculated from the $\rho_{\mathrm{b}}$ and skeletal density $\left(\rho_{\mathrm{s}}\right)$ of the aerogel. The surface areas $(\sigma)$ and pore size distribution of the PI aerogel were measured by $\mathrm{N}_{2}$ adsorption and desorption isotherms, using the Brunauer-Emmet-Teller (BET) method. As deduced from the $\mathrm{N}_{2}$ adsorption-desorption isotherm shown in Figure 4, the PI aerogel shows BET surface area of $428.6 \mathrm{~m}^{2} / \mathrm{g}$. The pore size distribution of PI aerogel calculated by Barret-Joyner-Halenda (BJH) method (Figure 4b) indicates that the average pore diameter in PI aerogel is $19.2 \mathrm{~nm}$. In addition, it can be seen from Figure 4 that PI aerogel showed rapid increases in adsorbed volumes at relative pressure above 0.9 and the desorption plots exhibited narrow loops. All this information indicates that both mesoporous and macroporous structures exist in the PI aerogel.

Table 1. Structural parameters and thermal properties of the PI aerogel

\begin{tabular}{|c|c|c|c|c|c|c|c|c|}
\hline Sample & $\begin{array}{c}\rho_{\mathbf{b}^{\mathrm{a}}} \\
{\left[\mathrm{g} / \mathrm{cm}^{3}\right]}\end{array}$ & $\begin{array}{c}\rho_{\mathrm{s}}^{\mathrm{b}} \\
{\left[\mathrm{g} / \mathrm{cm}^{3}\right]}\end{array}$ & $\begin{array}{c}\text { Porosity }^{\mathrm{c}} \\
{[\%]}\end{array}$ & $\begin{array}{c}\sigma^{\mathrm{d}} \\
{\left[\mathrm{m}^{2} / \mathrm{g}\right]}\end{array}$ & $\begin{array}{c}d^{\mathrm{e}} \\
{[\mathrm{nm}]}\end{array}$ & $\begin{array}{l}T_{5 \%}{ }^{\mathrm{f}} \\
{\left[{ }^{\circ} \mathrm{C}\right]}\end{array}$ & $\begin{array}{c}R_{\mathrm{w} 750^{\mathrm{g}}} \\
{[\%]}\end{array}$ & $\begin{array}{c}T_{\mathrm{g}}^{\mathrm{h}} \\
{\left[{ }^{\circ} \mathbf{C}\right]}\end{array}$ \\
\hline PI aerogel & 0.21 & 1.46 & 85.6 & 428.6 & 19.2 & 502 & 66.7 & 358.3 \\
\hline
\end{tabular}

${ }^{\mathrm{a} B u l k}$ density. ${ }^{\mathrm{b}}$ Skeletal density. ${ }^{\mathrm{c}}$ Calculated by $1-\left(\rho_{\mathrm{b}} / \rho_{\mathrm{s}}\right) .{ }^{\mathrm{d}}$ Brunauer-Emmett-Teller (BET) surface area. ${ }^{\mathrm{e}}$ Average pore diameter from the $\mathrm{BJH}$ desorption plot. ${ }^{\mathrm{f}}$ Temperature at $5 \%$ weight loss. ${ }^{\mathrm{g}}$ Residual weight ratio at $750^{\circ} \mathrm{C}$ in nitrogen. ${ }^{\mathrm{h}}$ Glass transition temperature.
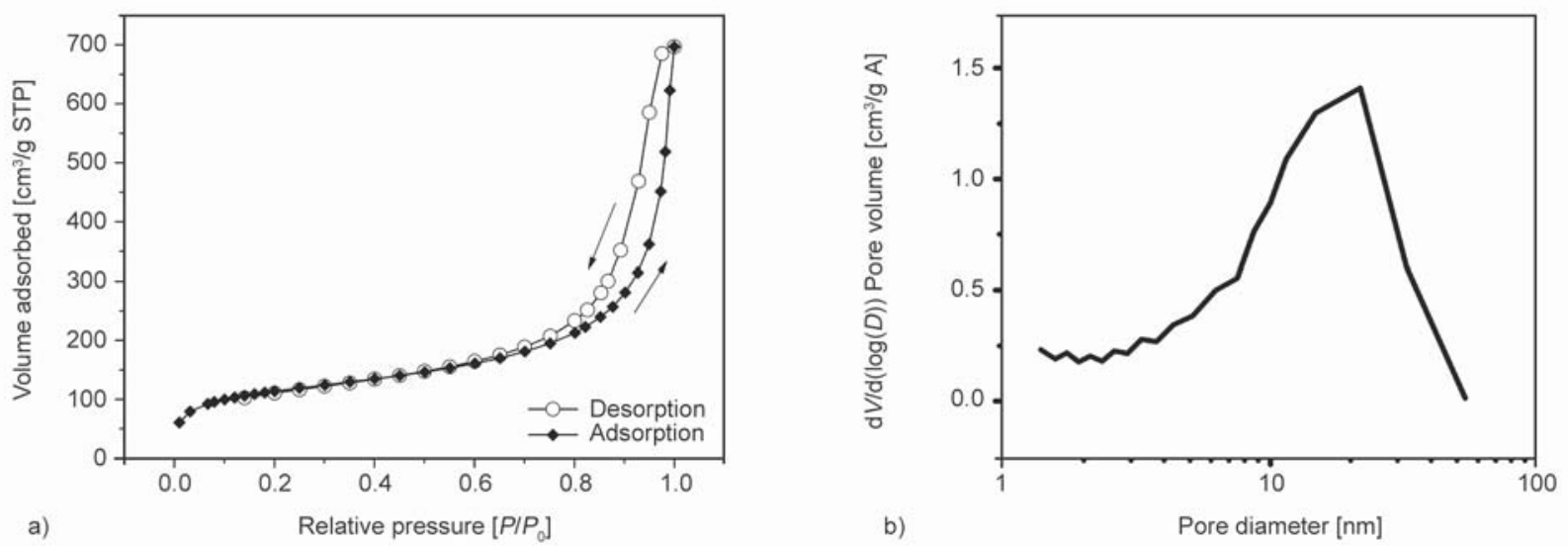

Figure 4. (a) $\mathrm{N}_{2}$ adsorption-desorption isotherm data for PI aerogel. (b) pore size distribution plot (BJH plot) 


\subsection{Thermal properties}

Thermal properties of the PI aerogel were evaluated by thermogravimetric analyses (TGA) and thermal mechanical analyses (TMA) measurements and the data were tabulated in Table 1 . The TGA measurements of the PI aerogels were performed in nitrogen from 50 to $750^{\circ} \mathrm{C}$ and the results are shown in Figure 5. From the plot, it can be observed that the aerogel showed good thermal stability up to $450^{\circ} \mathrm{C}$. The smooth plots around $300^{\circ} \mathrm{C}$ indicated the complete remove of residual NMP solvent by the supercritical drying procedure and the complete imidization in the system. The $5 \%$ weight loss temperatures $\left(T_{5 \%}\right)$ are $505^{\circ} \mathrm{C}$ and the residual weight ratio (char yield) of the aerogel at $750^{\circ} \mathrm{C}$ is $66.7 \%$ in nitrogen, indicating good thermal stability of the aerogel.

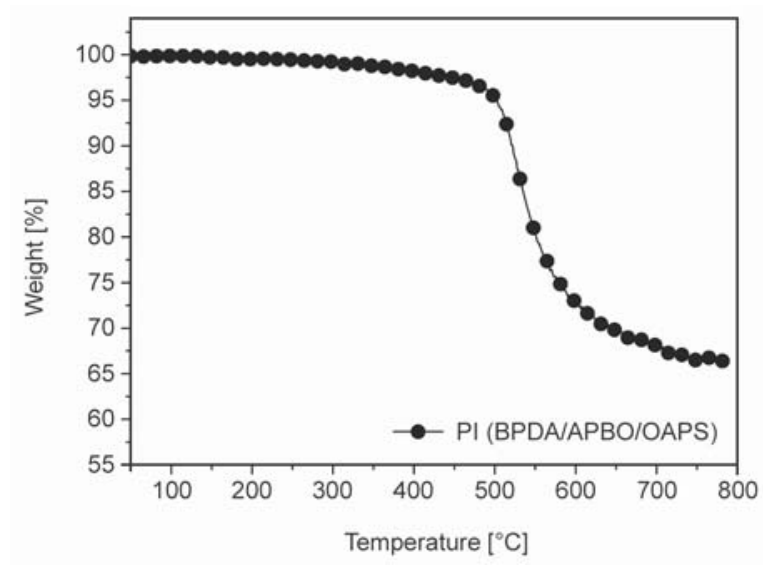

Figure 5. TGA plot of PI aerogel

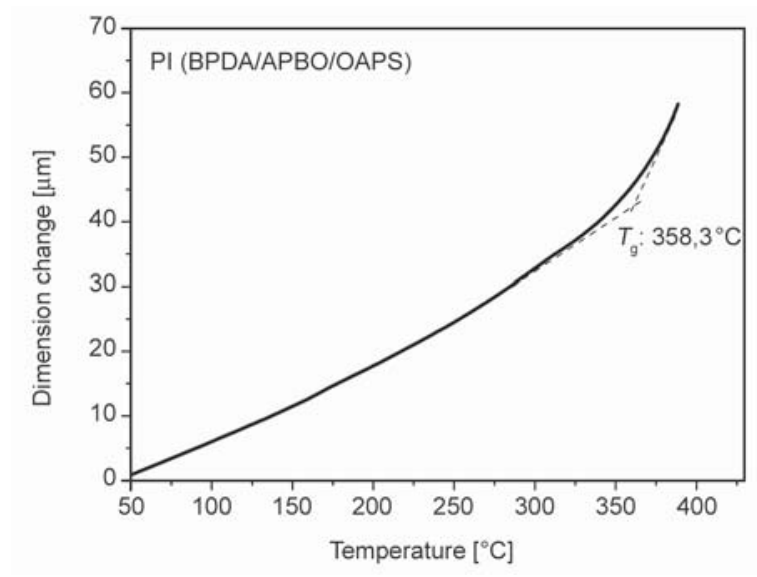

Figure 6. TMA plot of PI aerogel
The dimensional changes of aerogel at elevated temperatures were investigated by TMA measurements, as depicted in Figure 6. The aerogel showed expansion behavior after the occurrence of glass transition around $350{ }^{\circ} \mathrm{C}$. A $T_{\mathrm{g}}$ value was recorded at $358.3^{\circ} \mathrm{C}$ for the aerogel. This value is much higher than those of common polymer aerogels, which can guarantee the good reliability of the aerogel in ULSI fabrication.

\subsection{Dielectric properties}

The dielectric properties of the PI aerogel, including surface $\left(\rho_{\mathrm{s}}\right)$ and volume $\left(\rho_{\mathrm{v}}\right)$ resistivity, dielectric strength, dielectric constant and dissipation factor were investigated. These dielectric parameters are critical for their applications in ULSI applications. As shown in Table 2, the $\rho_{\mathrm{v}}$ and $\rho_{\mathrm{s}}$ values for the aerogel are $5.45 \cdot 10^{14} \Omega \cdot \mathrm{cm}$ and $8.74 \cdot 10^{13} \Omega$, respectively, indicating excellent electrical insulation properties.

The dielectric breakdown strength of the aerogel is $132 \mathrm{kV} / \mathrm{cm}$ at a thickness of $2.5 \mathrm{~mm}$ in our measurement. This value is a bit higher than that expected for porous materials. Similar phenomenon has also been observed by Hrubesh and Pekala [34] in their research on inorganic silica aerogels. In their investigation, the dielectric strength of $128 \mathrm{kV} / \mathrm{cm}$ was recorded for silica aerogels and this value was higher than those of common ceramics, such as alumina $(110 \mathrm{kV} / \mathrm{cm})$ although lower than those of pure polymers $(160-500 \mathrm{kV} / \mathrm{cm})$. The authors ascribed this unexpected high dielectric strength for aerogels to the small pore sizes in the air-filled aerogels. The pore sizes are of the same order as the mean free path for electron collisions. Thus, electrons in aerogel pores tend to collide with the solid before gaining sufficient kinetic energy to ionize upon impact. In the current work, the dielectric strength of $132 \mathrm{kV} / \mathrm{cm}$ at a thickness of $2.5 \mathrm{~mm}$ was recorded, which is comparable to that of inorganic silica aerogels.

We further investigated the dielectric breakdown behavior for the PI aerogel. Figure 7 compares the surface macro- and micro-topographies of PI aerogel before and after dielectric breakdown under high

Table 2. Dielectric properties of the PI aerogel

\begin{tabular}{|l|c|c|c|c|c|c|}
\hline & $\begin{array}{c}\boldsymbol{\rho}_{\mathbf{v}}{ }^{\mathbf{a}} \\
{[\mathbf{\Omega} \cdot \mathbf{c m}]}\end{array}$ & $\begin{array}{c}\boldsymbol{\rho}_{\mathbf{s}}{ }^{\mathbf{a}} \\
{[\mathbf{\Omega}]}\end{array}$ & $\begin{array}{c}\boldsymbol{d}^{\mathbf{b}} \\
{[\mathbf{m m}]}\end{array}$ & $\begin{array}{c}\boldsymbol{D}_{\mathbf{s}^{\mathbf{c}}} \\
{[\mathbf{k V} / \mathbf{c m}]}\end{array}$ & $\boldsymbol{k}^{\mathbf{d}}$ & $\boldsymbol{\delta}^{\mathrm{e}}$ \\
\hline PI aerogel & $5.45 \cdot 10^{14}$ & $8.74 \cdot 10^{13}$ & 2.5 & 132 & 1.15 & 0.0023 \\
\hline
\end{tabular}

${ }^{\mathrm{a}} \rho_{\mathrm{V}}$ and $\rho_{\mathrm{s}}$ : volume and surface resistivity at $23^{\circ} \mathrm{C}$ and $50 \%$ relative humidity, respectively; ${ }^{\mathrm{b} P I}$ aerogel thickness for $k$ measurements; ${ }^{\mathrm{c}} \mathrm{di}-$

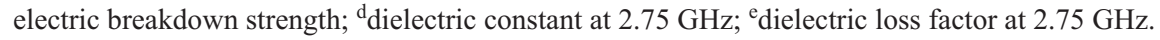


voltage. From the illustration, we can obviously observe that high level electrical voltage induces not only the dielectric breakdown, but apparent surface ablation phenomena in the tested area. Many pinholes were observed at the tested area, indicating dielectric breakdown of the PI solid. Basically, the dielectric properties of aerogels are dominated by the large volume fraction of trapped gas in the pores. However, during our measurement for dielectric breakdown, bright spark was observed at the moment of electrical breakdown, indicating a gaseous discharge. Meanwhile, high voltage breakdown occurred in the dense PI solid. Thus, the dielectric breakdown for PI aerogel might be ascribed to the simultaneous actions of high voltage to the trapped air and the dense PI solid. High temperature induced by the air discharge caused the surface ablation of the aerogel. At the same time, the instantaneous high temperature caused the expansion of the trapped air in the aerogel, resulting in the swelling at the surface of the

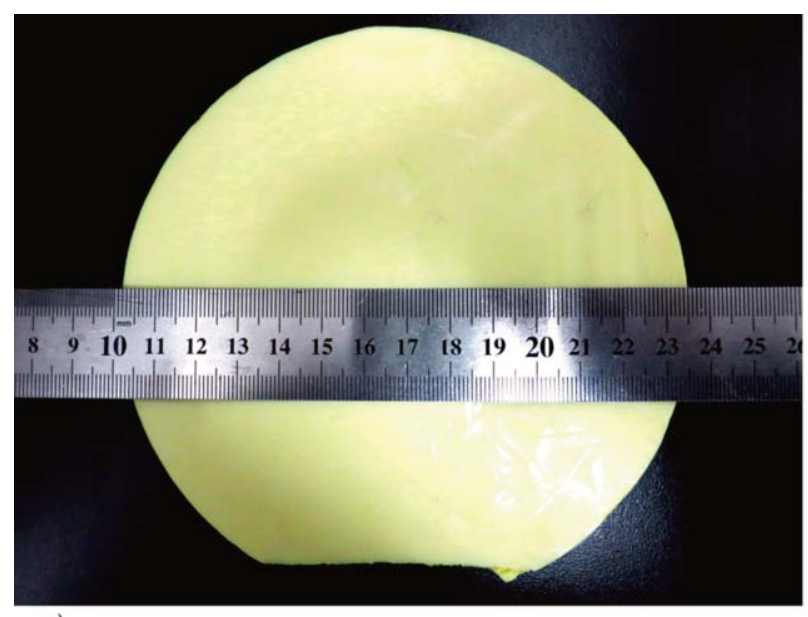

a)

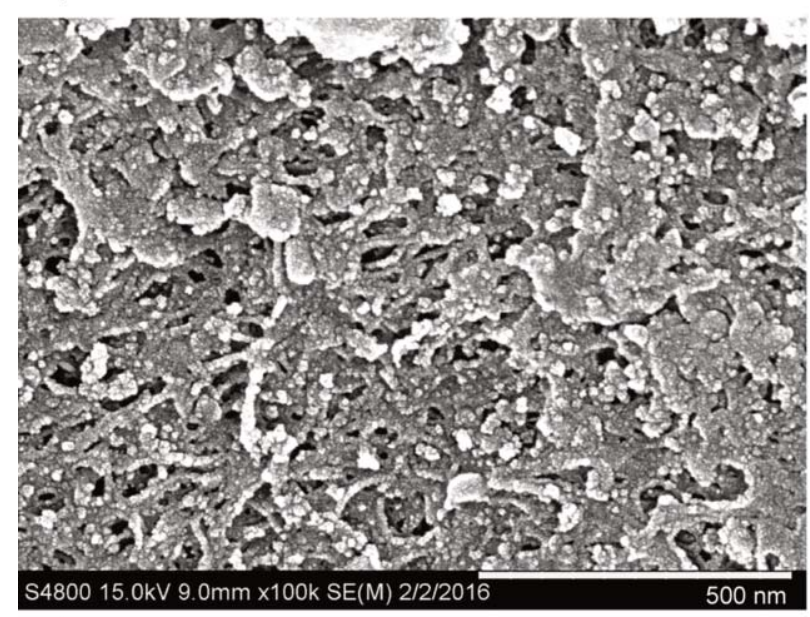

c) aerogel (Figure 7b). Nevertheless, the high dielectric breakdown strength makes the current PI aerogel to be effective and lightweight dielectric insulators for high-voltage insulating applications.

The broadband dielectric constant $(k)$ and dissipation factor $(\delta)$ of PI aerogel in the frequency range of 2$12 \mathrm{GHz}$ were measured at room temperature and the curve is illustrated in Figure 8. The monolithic PI

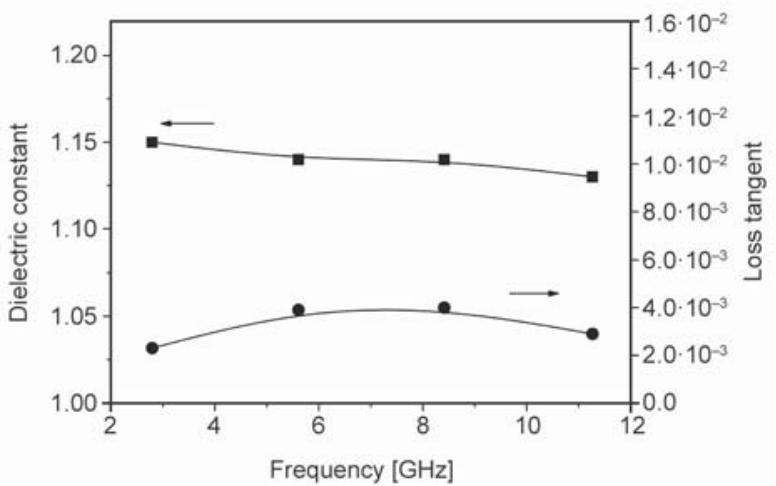

Figure 8. Dielectric constant $(k)$ and loss tangent for PIA as a function of frequency

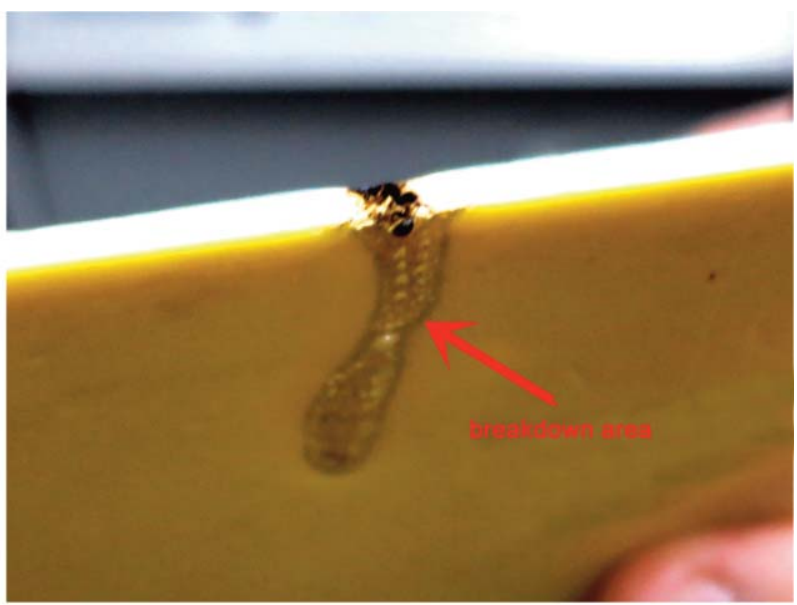

b)

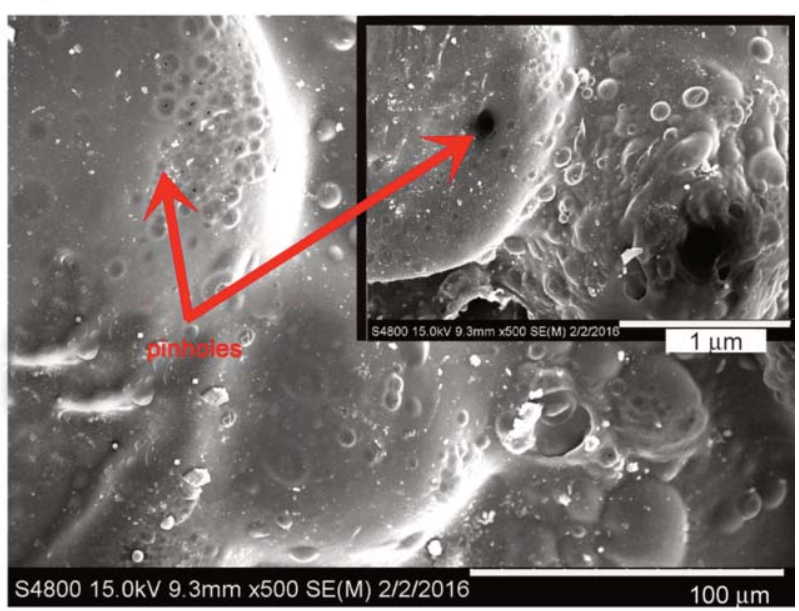

d)

Figure 7. Surface macro- and micro-topographies of PI aerogel before (a) and after (b) dielectric breakdown, (c) SEM image before dielectric breakdown, (d) SEM image after dielectric breakdown 
aerogel sample $(50 \mathrm{~mm} \times 30 \mathrm{~mm} \times 2.5 \mathrm{~mm})$ exhibited nearly a constant $k$ value (1.15-1.13) over the entire frequency range. Thus, introduction of air within the PI reduced the $\mathrm{k}$ value significantly. The loss tangent $(\delta)$ value of PI aerogel also changed in a narrow range of $2.3 \cdot 10^{-3}-4.0 \cdot 10^{-3}$. The frequency-independent feature of $k$ and $\delta$ values for PI aerogel is mainly attributed to the high air loading (porosity: $85.6 \%$ ) in its structure. The phenomena indicate that the dielectric constant of the PI aerogel is dominated by the trapped air rather than by the solid PI matrix.

\section{Conclusions}

New PI aerogel was synthesized from BPDA, APBO and OAPS via two-step chemical imidization procedure, followed by $\mathrm{ScCO}_{2}$ drying procedure. The original purpose of molecular design aiming at developing functional PIs with potential applications as ILDs for ULSI was successfully achieved by the derived PI aerogel. Experimental results revealed that the current PI aerogel possessed various advantages compared with the other organic aerogels reported before. First, the polymer exhibited excellent thermal stability and $T_{\mathrm{g}}$ over $350^{\circ} \mathrm{C}$, which is among the most thermally stable polymers reported in the literature. Secondly, the current PI aerogel shows excellent dielectric characteristics, including ultra-low $\mathrm{k}$ value and dissipation factor over a broad frequency range of 2-12 GHz, high surface and volume resistivity, and high dielectric strength. The $k$ value around 1.15 at a frequency of $2.75 \mathrm{GHz}$ is one the lowest values for PI materials reported in the literature. Thus, good combined properties make the PI aerogel a good candidate as interlayer dielectric for advanced semiconductor chip interconnection.

\section{Acknowledgements}

Financial support from the Fundamental Research Funds of Beijing Jiaotong University (E14JB00130), National Basic Research Program (973 Program) of China (2014CB643605), and National Natural Science Foundation of China (51173188) are gratefully acknowledged.

\section{References}

[1] Volksen W., Miller R-D., Dubois G.: Low dielectric constant materials. Chemical Reviews, 110, 56-110 (2010). DOI: $10.1021 /$ cr9002819

[2] Drobny J-G.: Polymers for electricity and electronics. Materials, properties, and applications. Wiley, New Jersey (2012).
[3] Maier G.: Low dielectric constant polymers for microelectronics. Progress in Polymer Science, 26, 3-65 (2001). DOI: 10.1016/S0079-6700(00)00043-5

[4] Liaw D-J., Wang K-L., Huang Y-C., Lee K-R., Lai J-Y., Ha S-K.: Advanced polyimide materials: Syntheses, physical properties and applications. Progress in Polymer Science, 37, 907-974 (2012). DOI: 10.1016/j.progpolymsci.2012.02.005

[5] Liu Y., Qian C., Qu L., Wu Y., Zhang Y., Wu X., Zou B., Chen W., Chen Z., Chi Z., Liu S., Chen X., Xu J.: A bulk dielectric polymer film with intrinsic ultralow dielectric constant and outstanding comprehensive properties. Chemistry of Materials, 27, 6543-6549 (2015). DOI: $10.1021 /$ acs.chemmater.5b01798

[6] Simpson J-O., St. Clair A-K.: Fundamental insight on developing low dielectric constant polyimides. Thin Solid Films, 308-309, 480-485 (1997).

DOI: $10.1016 / \mathrm{S} 0040-6090(97) 00481-1$

[7] Kohl P-A.: Low-dielectric constant insulators for future integrated circuits and packages. Chemical and Biomolecular Engineering, 2, 379-401 (2011).

DOI: 10.1146/annurev-chembioeng-061010-114137

[8] Dhara M-G., Banerjee S.: Fluorinated high-performance polymers: Poly(arylene ether)s and aromatic polyimides containing trifluoromethyl groups. Progress in Polymer Science, 35, 1022-1077 (2010).

DOI: $10.1016 /$ j.progpolymsci.2010.04.003

[9] Taki K., Hosokawa K., Takagi S., Mabuchi H., Ohshima M.: Rapid production of ultralow dielectric constant porous polyimide films via $\mathrm{CO}_{2}$-tert-amine Zwitterioninduced phase separation and subsequent photopolymerization. Macromolecules, 46, 2275-2281 (2013). DOI: $10.1021 / \mathrm{ma302406m}$

[10] Carter K. R., DiPietro R-A., Sanchez M-I., Swanson SA.: Nanoporous polyimides derived from highly fluorinated polyimide/poly(propylene oxide) copolymers. Chemistry of Materials, 13, 213-221 (2001). DOI: $10.1021 / \mathrm{cm} 990707 \mathrm{o}$

[11] Fu G. D., Zong B. Y., Kang E. T., Neoh K. G., Lin C. C., Liaw D. J.: Nanoporous low-dielectric constant polyimide films via poly(amic acid)s with RAFT-graft copolymerized methyl methacrylate side chains. Industrial Engineering Chemistry Research, 43, 6723-6730 (2004). DOI: $10.1021 / \mathrm{ie} 0498807$

[12] Zha J-W., Jia H-J., Wang H-Y., Dang Z-M.: Tailored ultralow dielectric permittivity in high-performance fluorinated polyimide films by adjusting nanoporous characterisitics. The Journal of Physical Chemistry C, 116, 23676-23681 (2012).

DOI: $10.1021 / \mathrm{jp} 305286 \mathrm{r}$

[13] Zhao G., Ishizaka T., Kasai H., Hasegawa M., Furukawa T., Nakanishi H., Oikawa H.: Ultralow-dielectric-constant films prepared from hollow polyimide nanoparticles possessing controllable core sizes. Chemistry of Materials, 21, 419-424 (2009).

DOI: $10.1021 / \mathrm{cm} 802989 \mathrm{u}$ 
[14] Leu C-M., Chang Y-T., Wei K-H.: Polyimide-side-chain tethered polyhedral oligomeric silsesquioxane nanocomposites for low-dielectric film applications. Chemistry of Materials, 15, 3721-3727 (2004).

DOI: $10.1021 / \mathrm{cm} 030393 \mathrm{~b}$

[15] Nitta S. V., Pisupatti V., Jain A., Wayner Jr P. C., Gill W. N., Plawsky J. L.: Surface modified spin-on xerogel films as interlayer dielectrics. Journal of Vacuum Science and Technology, B, 17, 205-212 (1999). DOI: 10.1116/1.590541

[16] Yan P., Zhou B., Du A.: Synthesis of polyimide crosslinked silica aerogels with good acoustic performance. RSC Advances, 4, 58252-58259 (2014). DOI: $10.1039 / \mathrm{c} 4 \mathrm{ra} 08846 \mathrm{~h}$

[17] Leventis N., Sotiriou-Leventis C., Chandrasekaran N., Mulik S., Larimore Z-J., Lu H-B., Churu G., Mang J-T.: Multifunctional polyurea aerogels from isocyanates and water. A structure-property case study. Chemistry of Materials, 22, 6692-6710 (2010).

DOI: $10.1021 / \mathrm{cm} 102891 \mathrm{~d}$

[18] Bang A., Buback C., Sotiriou-Leventis C., Leventis N.: Flexible aerogels from hyperbranched polyurethanes: Probing the role of molecular rigidity with poly(urethane acrylates) versus poly(urethane norbornenes). Chemistry of Materials, 26, 6979-6993 (2014). DOI: $10.1021 / \mathrm{cm} 5031443$

[19] Meador M. A. B., Malow E. J., Silva R., Wright S., Quade D., Vivod S. L., Guo H., Guo J., Cakmak M.: Mechanically strong, flexible polyimide aerogels crosslinked with aromatic triamine. ACS Applied Material Interfaces, 4, 536-544 (2012).

DOI: $10.1021 / \mathrm{am} 2014635$

[20] Guo H. Q., Meador M. A. B., McCorkle L., Quade D. J., Guo J., Hamilton B., Cakmak M., Sprowl G.: Polyimide aerogels cross-linked through amine functionalized polyoligomeric silsesquioxane. ACS Applied Material Interfaces, 3, 546-552 (2011).

DOI: $10.1021 / \mathrm{am} 101123 \mathrm{~h}$

[21] Meador M. A. B., Alemán C. R., Hanson K., Ramirez N., Vivod S. L., Wilmoth N., McCorkle L.: Polyimide aerogels with amide cross-Links: A low cost alternative for mechanically strong polymer aerogels. ACS Applied Material Interfaces, 7, 1240-1249 (2015). DOI: $10.1021 / \mathrm{am} 507268 \mathrm{c}$

[22] Liu P., Tran T-Q., Fan Z., Duong H. M.: Formation mechanisms and morphological effects on multi-properties of carbon nanotube fibers and their polyimide aerogel-coated composites. Composites Science and Technology, 117, 114-120 (2015).

DOI: $10.1016 /$ j.compscitech.2015.06.009

[23] Meador M. A. B., Wright S., Sandberg A., Nguyen B. N., van Keuls F. W., Mueller C. H., Rodriguez-Solís R., Miranda F. A.: Low dielectric polyimide aerogels as substrates for lightweight patch antennas. ACS Applied Material Interfaces, 4, 6346-6353 (2012).

DOI: $\underline{10.1021 / \mathrm{am} 301985 \mathrm{~s}}$
[24] Meador M. A. B., McMillon E., Sandberg A., Barrios E., Wilmoth N. G., Mueller C. H., Miranda F. A.: Dielectric and other properties of polyimide aerogels containing fluorinated blocks. ACS Applied Materials and Interfaces, 6, 6062-6068 (2014).

DOI: $10.1021 / \mathrm{am} 405106 \mathrm{~h}$

[25] Shen D., Liu J., Yang H., Yang S.: Intrinsically highly hydrophobic semi-alicyclic fluorinated polyimide aerogel with ultralow dielectric constants. Chemistry Letters, 42, 1230-1232 (2013).

DOI: $10.1246 / \mathrm{cl} .130623$

[26] Ko H-H., Chong J. Y-T., Lam D. C. C.: Low-stress ultra-low dielectric porous polymer for high density applications: A review. in 'Proceeding of the $13^{\text {th }}$ IEEE International Conference on Nanotechnology, Beijing, China' 34-38 (2013). DOI: 10.1109/NANO.2013.6721031

[27] Fukukawa K-I., Shibasaki Y., Ueda M.: A photosensitive semi-alicyclic poly(benzoxazole) with high transparency and low dielectric constant. Macromolecules, 37, 8256-8261 (2004).

DOI: $10.1021 / \mathrm{ma} 049063 \mathrm{i}$

[28] Liao W-H., Yang S-Y., Hsiao S-T., Wang Y-S., Li S-M., Ma C-C. M., Tien H-W., Zeng S-J.: Effect of octa (aminophenyl) polyhedral oligomeric silsesquioxane functionalized graphene oxide on the mechanical and dielectric properties of polyimide composites. ACS Applied Materials and Interfaces, 6, 15802-15812 (2014). DOI: $10.1021 / \mathrm{am} 504342 \mathrm{j}$

[29] Shen D., Liu J., Yang H., Yang S.: Highly thermally resistant and flexible polyimide aerogels containing rigidrod biphenyl, benzimidazole, and triphenylpyridine moieties: Synthesis and characterization. Chemistry Letters, 42, 1545-1547 (2013).

DOI: $10.1246 / \mathrm{cl} .130758$

[30] Aegerter M. A., Leventis N., Koebel M. M.: Aerogel handbook. Springer, New York (2011).

[31] Cooper A. I.: Polymer synthesis and processing using supercritical carbon dioxide. Journal of Materials Chemistry, 10, 207-234 (2000).

DOI: 10.1039/A906486I

[32] Li L., Yalcin B., Nguyen B. N., Meador M. A. B., Cakmak M.: Flexible nanofiber-reinforced aerogel (xerogel) synthesis, manufacture, and characterization. Applied Materials and Interfaces, 1, 2491-2501 (2009). DOI: $10.1021 / \mathrm{am} 900451 \mathrm{x}$

[33] Pierre A. C., Pajonk G. M.: Chemistry of aerogels and their applications. Chemical Reviews, 102, 4243-4265 (2002).

DOI: $10.1021 / \mathrm{cr} 0101306$

[34] Hrubesh L. W., Pekala R. W.: Dielectric properties and electronic applications of aerogels. in 'Sol-gel processing and applications' (ed.: Attia Y. A.) Plenum Press, New York, 363-367 (1994).

DOI: $10.1007 / 978-1-4615-2570-731$ 